\title{
Association and path coefficient analysis among yield attributes and berry yield in black pepper (Piper nigrum L.)
}

\author{
M S Shivakumar ${ }^{1, *} \&$ K V Saji ${ }^{2}$ \\ ${ }^{1}$ ICAR-Indian Institute of Spices Research, Regional Station, \\ Appangala, Madikeri-571 201, Karnataka. \\ ${ }^{2} I C A R-I n d i a n$ Institute of Spices Research, Kozhikode-673 012, Kerala. \\ *E-mail: shivakumar.s@icar.gov.in
}

Received 30 October 2019; Revised 09 December 2019; Accepted 16 December 2019

\begin{abstract}
Eighty two germplasm accessions of black pepper aggregated from pepper cultivating tracts of Karnataka, Kerala, Goa and Maharashtra were characterized for 17 quantitative traits as per the IPGRI descriptors during 2018-19 at the field gene bank of ICAR-Indian Institute of Spices Research, Experimental Farm, Kozhikode. Wide range and high coefficient of variation (CV) were recorded for dry berry weight, fresh berry weight and number of spikes vine ${ }^{-1}$ whereas, lower CV was observed for berry size. Fresh berry weight showed significant positive correlation with dry berry weight followed by number of spikes vine ${ }^{-1}$ whereas, number of immature berries spike ${ }^{-1}$ and berry size showed significant negative association with setting percentage. High positive direct effect of fresh berry weight on dry berry weight was observed during path analysis. Both fresh rachis weight and number of spikes vine ${ }^{-1}$ had indirect positive effects on dry berry weight through fresh berry weight. Residual effect was meagre suggesting that the 17 quantitative traits explained 99\% variability. Traits like number of spikes vine ${ }^{-1}$ and fresh berry weight are the important traits that need to be augmented during improvement of black pepper for yield.
\end{abstract}

Keywords: breeding, characterization, correlation, germplasm and path analysis

\section{Introduction}

Black pepper (Piper nigrum L.) is one of the oldest known spices, and has immensely influenced the geopolitical history of the world as it was a much sought-after commodity since ancient days. It is a self-pollinated, perennial climbing vine cultivated for its berries. Though native to humid tropical evergreen forest of Western Ghats of south India, now it is cultivated in other countries like Indonesia, Malaysia, Brazil, Sri Lanka, Vietnam, China etc. (Krishnamoorthy \& Parthasarathy 2009). Cultivar diversity is one of the principal components of diversity in black pepper and over 100 black pepper cultivars are established in India (Ravindran et al. 1997). The ICAR-Indian Institute of Spices Research (IISR) at Kozhikode, Kerala, maintains the world's largest collection of black pepper germplasm containing local landraces/cultivars 
and wild forms collected from the area of origin and related species. The collected germplasm accessions are characterized over time for various economic traits like yield, quality and resistance to stresses and the promising accessions are released as varieties (Sasikumar et al. 2004).

For any effective breeding strategy, the inter trait association of yield contributing traits need to be analysed. Correlation between themselves express only degree of traits inter relationships and does not say anything about the cause and effect. But path coefficient divides correlation coefficients into a measure of direct and indirect effects within a system of correlated traits. In any improvement program, for complex traits such as yield, for which direct selection is not competent, it is essential to measure the contribution of each of the component traits to the observed correlation and to partition the correlation into components of direct and indirect effect (Giriraji \& Vijaykumar 1974). Barring few studies about the traits association, direct and indirect effect of various traits on yield, this aspect in black pepper is not well studied (Ibrahim et al. 1985c; Thanuja \& Rajendran 2003). The objectives of the present study were to obtain and interpret information on the nature of association between berry yield and berry yield-related traits that have been organized into direct and indirect effects in a path diagram.

\section{Material and methods}

The material for the study consisted of 82 germplasm accessions collected from black pepper growing tracts of Kerala, Karnataka, Goa and Maharashtra. Present investigation was carried out at ICAR-IISR Experimental Station, Peruvannamuzhi, Kozhikode, Kerala. Recommended agronomic practices were followed to raise a good and healthy crop. Data were recorded during 2018-19 on 17 quantitative traits viz., plant height $[\mathrm{PH}](\mathrm{cm})$, lateral branch length [LBL] $(\mathrm{cm})$, nodes/lateral branch [NLB], leaf petiole length [LPT] $(\mathrm{cm})$, leaf length [LL] $(\mathrm{cm})$, leaf width $[\mathrm{LW}](\mathrm{cm})$, peduncle length
[PL] $(\mathrm{cm})$, spike length [SL] $(\mathrm{cm})$, number of immature berries spike ${ }^{-1}$ [NIMBS], number of matured berries spike ${ }^{-1}$ [NMBS], fruiting/setting percentage $[\mathrm{FP} / \mathrm{SP}](\%)$, berry size $[\mathrm{BS}](\mathrm{cm})$, fresh berry weight vine ${ }^{-1}[\mathrm{FBW}](\mathrm{g})$, fresh rachis weight vine ${ }^{-1}[F R W](g)$, number of spikes vine ${ }^{-}$ ${ }^{1}[\mathrm{NS}]$, dry berry weight vine ${ }^{-1}[\mathrm{DBW}](\mathrm{g})$ and dry recovery [DR] (\%) as per IPGRI descriptors (IPGRI 1995).

Analysis of variance using descriptive statistics such as mean, standard deviation (SD) and coefficient of variation (CV) for each of the 17 studied traits were calculated. Windostat version 8.6 from Indostat service Hyderabad, India was used for estimation of Pearson's correlation coefficient and Path co-efficient analysis (Dewey \& Lu 1959).

\section{Results and discussion}

Wide range of variation was observed for dry berry weight vine $^{-1}$, fresh berry weight vine $^{-1}$ and number of spikes vine ${ }^{-1}$ in the present investigation (Table 1). These traits also recorded highest coefficient of variation which are in agreement with Ibrahim et al. (1985a) and Preethi et al. (2018). Whereas, Pradeepkumar et al. (2003) observed high variation for fresh yield and berries spike ${ }^{-1}$. The range for traits indicated that phenotypic selection is desirable to gain desired improvement for traits.

Information about inter-trait association is of pivotal importance in indirect selection and for initiating effective breeding programmes (Bhatt \& Reddy 1981). Dry berry weight recorded high positive significant correlation $(\mathrm{P}<0.001)$ with fresh berry weight, fresh rachis weight and number of spikes vine ${ }^{-1}$ (Table 2). Leaf length and leaf width showed positive correlation between each other which is in accordance with Preethi et al. (2018). Number of matured berries and number of immature berries spike ${ }^{-1}$ showed significant positive correlation with setting percentage. However, number of immature berries spike ${ }^{-1}(-0.85)$ and berry size $(-0.22)$ showed significant negative association with setting percentage indicating that as number of 
Table 1. Mean performance, coefficient of variation and range for 17 quantitative traits in black pepper germplasm accessions

\begin{tabular}{|c|c|c|c|c|c|}
\hline \multirow[t]{2}{*}{ Trait } & \multirow[t]{2}{*}{ Mean } & \multirow[t]{2}{*}{$\mathrm{SD}$} & \multirow[t]{2}{*}{$\mathrm{CV}$} & \multicolumn{2}{|c|}{ Range } \\
\hline & & & & Min & Max \\
\hline Plant height $(\mathrm{cm})$ & 521.10 & 79.49 & 15.25 & 290.00 & 690.00 \\
\hline Lateral branch length $(\mathrm{cm})$ & 50.77 & 8.71 & 17.16 & 29.33 & 71.67 \\
\hline Nodes/LB & 21.07 & 7.35 & 34.91 & 11.00 & 42.33 \\
\hline Leaf petiole length $(\mathrm{cm})$ & 1.83 & 0.38 & 21.01 & 0.44 & 2.86 \\
\hline Leaf length $(\mathrm{cm})$ & 14.08 & 1.99 & 14.10 & 8.98 & 20.80 \\
\hline Leaf width $(\mathrm{cm})$ & 8.00 & 1.26 & 15.75 & 5.46 & 11.42 \\
\hline Peduncle length $(\mathrm{cm})$ & 1.24 & 0.32 & 25.90 & 0.44 & 2.04 \\
\hline Spike length (cm) & 9.04 & 1.62 & 17.96 & 4.72 & 13.32 \\
\hline Immature berries spike $^{-1}$ & 23.26 & 8.43 & 36.24 & 7.33 & 46.00 \\
\hline Matured berries spike ${ }^{-1}$ & 49.07 & 15.97 & 32.54 & 20.00 & 98.40 \\
\hline Fruiting \% & 67.37 & 11.44 & 16.98 & 30.30 & 89.09 \\
\hline Berry size $(\mathrm{cm})$ & 0.56 & 0.05 & 8.62 & 0.45 & 0.67 \\
\hline No. of spikes vine ${ }^{-1}$ & 364.26 & 188.58 & 51.77 & 56.00 & 821.00 \\
\hline Rachis weight (g) & 119.39 & 68.96 & 57.76 & 12.00 & 290.00 \\
\hline Fresh berry weight (g) & 1021.22 & 542.05 & 53.08 & 172.00 & 2851.00 \\
\hline Dry berry weight (g) & 326.07 & 180.03 & 55.21 & 48.00 & 925.00 \\
\hline Dry recovery (\%) & 31.91 & 4.39 & 13.74 & 19.23 & 41.27 \\
\hline
\end{tabular}

Where SD=Standard Deviation; $\mathrm{CV}=$ Coefficient of Variation

immature berries spike ${ }^{-1}$ and seed size reduces, setting percentage increases. Interestingly, peduncle length, berry size and dry recovery also showed significant negative correlation with setting percentage. Sujatha \& Namboothiri (1995) reported significant positive influence of spike length on yield. In our study, no significant correlation was observed between spike length and dry berry weight. Earlier studies revealed that fresh and dry yields were positively and significantly correlated with number of spikes and berries (Ibrahim et al. 1985b; Bekele et al. 2017; Sainamole et al. 2002).

Dry berry weight was used as a dependable trait for path coefficient analysis (Table 3 \& Fig. 1).
High $R^{2}(0.993)$ and very low residual effect (0.08) indicated that $99 \%$ of variation on dry berry yield has been accounted by 17 quantitative traits. Fresh berry weight showed high and positive direct effects (0.98) on dry berry weight depicting a true relationship between the two traits. Therefore, a direct selection through fresh berry weight might also be more effective. The fresh rachis weight and number of spikes vine ${ }^{-1}$ had significant positive correlation, but their direct effects were negligible implying that the indirect effects were the cause of correlation. Dry recovery had moderate direct positive effects on dry berry weight even though their association with dry berry weight was not significant. Both fresh rachis weight and number of spikes 


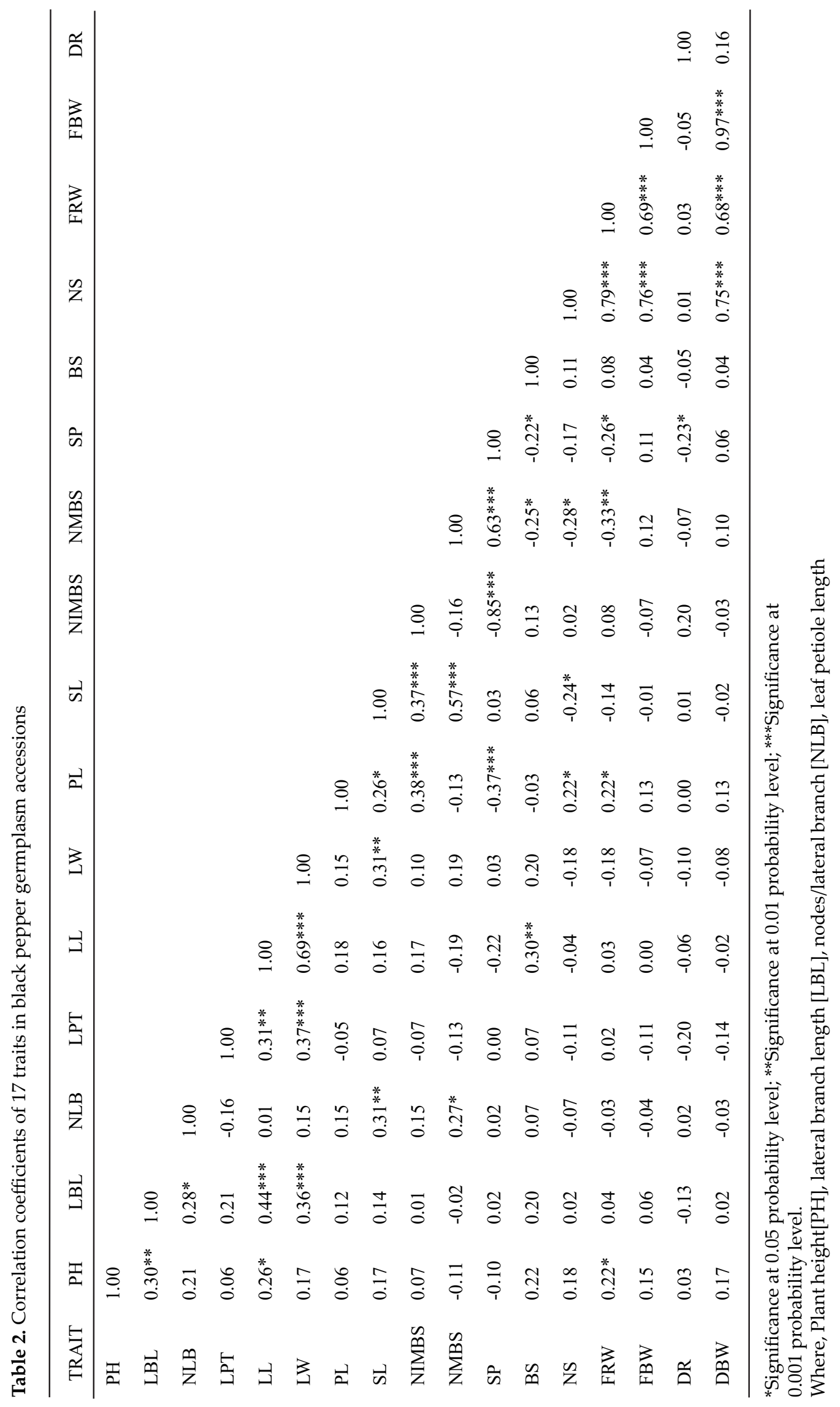




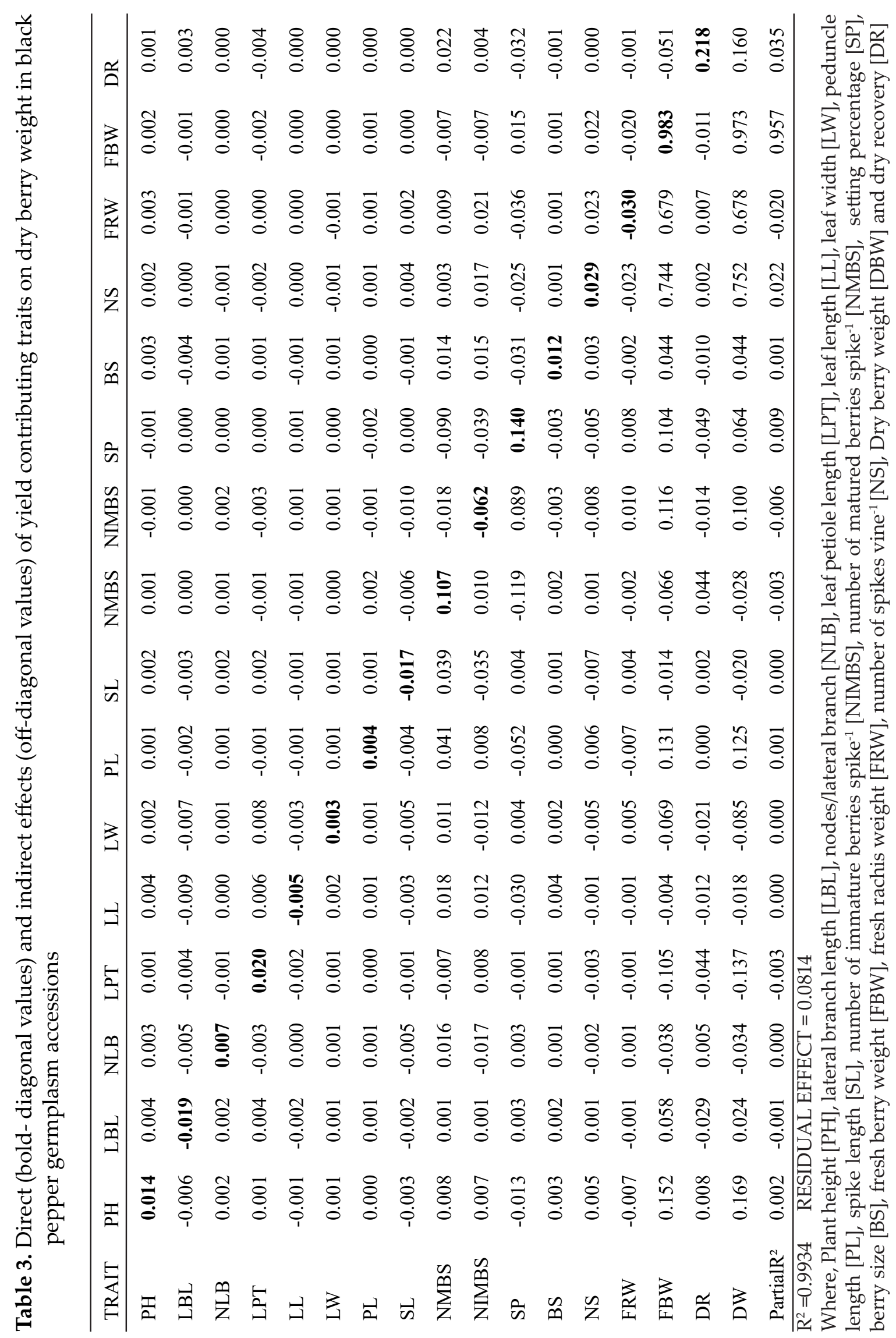




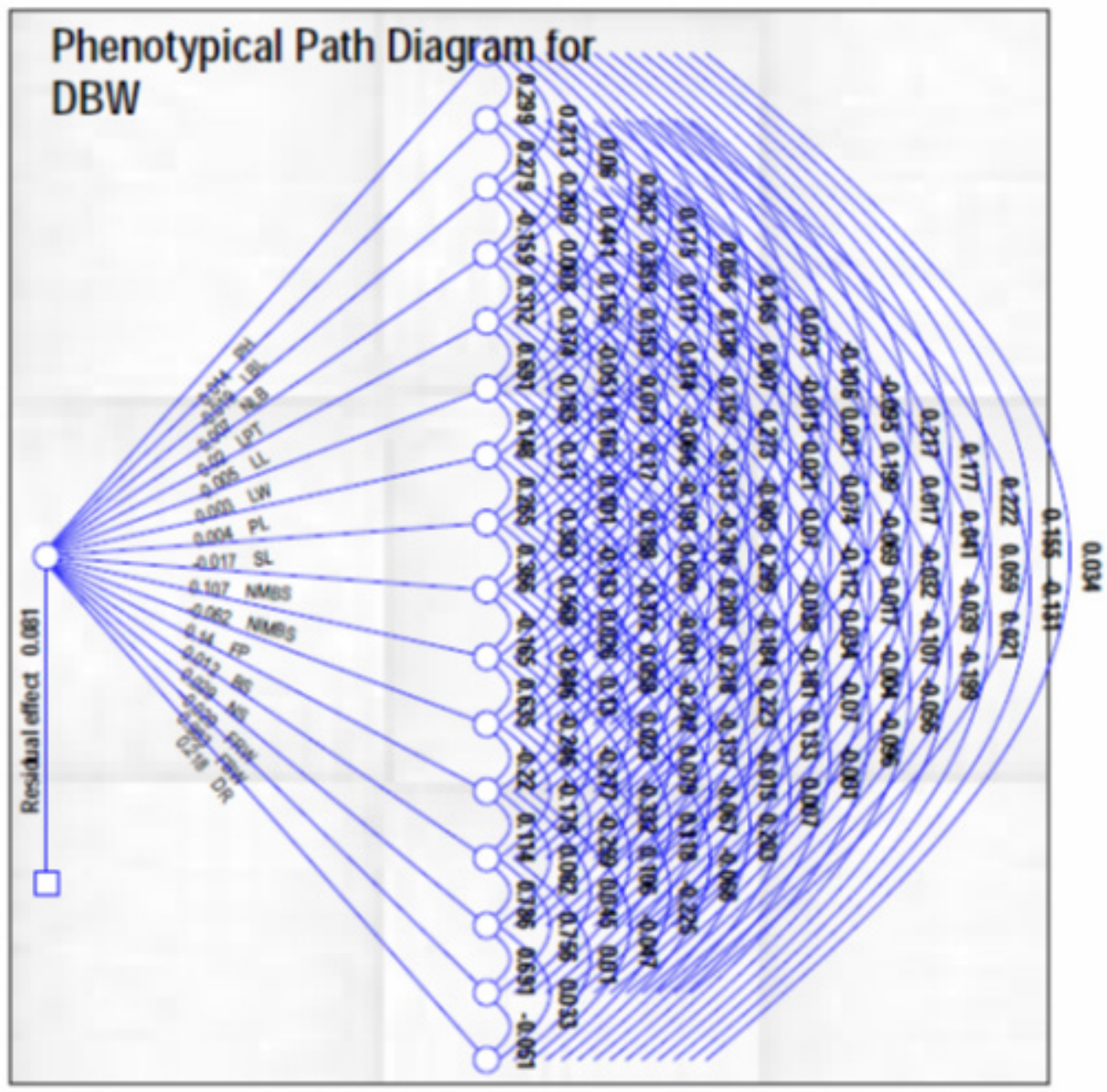

Fig. 1. Path diagram showing direct and indirect effects of quantitative traits on dry berry weight in black pepper germplasm accessions

vine $^{-1}$ had indirect positive effects on dry berry weight through fresh berry weight and hence they may be considered together for indirect selection. Rest of the traits showed negligible direct effect and indirect effects of berry weight components on each other and were weak for dry berry weight. Those weak indirect effects and correlations resulted mainly from weak correlations. Fresh berry weight showed a high correlation and direct effect towards dry berry yield and also had an indirect effect through fresh rachis weight and number of spikes vine ${ }^{-1}$. Therefore, this trait may be important for direct selection purposes. Similar high direct effect on dry berry weight was previously reported (Ibrahim et al. 1985c; Thanuja \& Rajendran 2003).
According to Singh \& Chaudhary (1985), if the correlation coefficient is positive but the direct effect is negative or negligible the indirect effects might be the causal factor of association.

The present study indicated that there is wide range of genetic variation in black pepper germplasm and helped in identification of some important traits viz., fresh berry weight, fresh rachis weight and number of spikes vine ${ }^{-1}$ which directly or indirectly have a positive effect on the dry berry weight in black pepper. The traits identified are the important traits that need to be augmented during improvement of black pepper for yield. 


\section{References}

Bhatt D \& Reddy T P 1981 Correlations and path analysis in castor (Ricinus communis L.). Can. J. Genet. Cyt. 23: 525-531.

Bekele D, Gedebo A \& Mitiku H 2017 Morpho-genetic variability and character correlation among thirteen black pepper accessions. Int. J. Agri. For. 7: 52-55.

Dewey D R \& Lu K H 1959 A correlation and path coefficient analysis of components of crescent wheat grass seed production. Agron. J. 51: 515-518.

Giriraji K \& Vijayakumar S 1974 Path coefficient analysis of yield attributes in mung bean. Indian J. Genet. 34: 27-30.

Ibrahim K K, Pillay V S \& Sasikumaran S 1985a Variability, heritability and genetic advance for certain quantitative characters in black pepper. Agri. Res. J. Kerala 23: 45-48.

Ibrahim K K, Pillai V S \& Sasikumaran S 1985b Genotypic and phenotypic correlation among yield and its components in black pepper (Piper nigrum L.). Agri. Res. J. Kerala 23: $150-153$.

Ibrahim K K, Pillay V S \& Sasikumaran S 1985c Path coefficient analysis of some yield components in black pepper (Piper nigrum L.). Indian Spices 22: 21-25.

IPGRI 1995 International Plant Genetic Resources Institute, Rome Italy, ISBN 92-9043-241-1.

Krishnamoorthy B \& Parthasarathy V A 2009 Improvement of black pepper, $\mathrm{CAB}$ Reviews Perspectives in Agriculture Veterinary Science Nutrition and Natural Resources, Vol. 4, pp.1749-8848.
Pradeepkumar T, Sajith Babu D, Aipe K C \& Samuel Mathew 2003 Clonal variability in black pepper hybrid panniyur-1. J. Spices Arom. Crops 12: 154-157.

Preethy T T, Aswathy T S, Sathyan T, Dhanya M K \& Murugan M 2018 Performance, diversity analysis and character association of black pepper (Piper nigrum L.) accessions in the high altitude of Idukki district, Kerala. J. Spices Arom. Crops 27: 17-21.

Ravindran P N, Balakrishnan R \& Babu K N 1997 Morphological studies on black pepper (Piper nigrum L.) I. Cluster analysis of black pepper cultivars. J. Spices Arom. Crops 6: 09-20.

Sainamole Kurian P, Backiyarani S, Josephrajkumar A \& Murugan M 2002 Varietal evaluation of black pepper for yield, quality and anthracnose disease resistance in Idukki District, Kerala. J. Spices Arom. Crops 11: 122-124.

Sasikumar B, Haridas P, George J K, Saji K V, John Zachariah T, Ravindran P N, Nirmal Babu K, Krishnamoorthy B, Mathew P A \& Parthasarathy V A 2004 'IISR Thevam', 'IISR Malabar Excel', 'IISR Girimunda' - three new black pepper clones. J. Spices Arom. Crops 13: 01-05.

Singh R K \& Chaundry B D 1985 Biometrical methods in quantitative genetic analysis. Kalayani Publishers, New Delhi-Ludhiana 78: 318.

Sujatha R \& Namboothiri K M N 1995 Influence of plant characters on yield of black pepper (Piper nigrum L.). J. Trop. Agri. 33: 11-15.

Thanuja T V \& Rajendran P C 2003 Influence of plant characters on dry yield of black pepper (Piper nigrum L.). Proceedings of XIII Swadeshi Science Congress 47-51. 